\title{
LA SITUACIÓN DE LA MUJER EN HONDURAS
}

\section{YOLANDA DOMENECH LÓPEZ}

Profesora ayudante del Area de Trabajo Social y Servicios Sociales.

Universidad de Alicante.

\section{INTRODUCCIÓN}

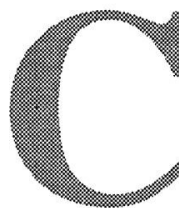

omo consecuencia de la obtención de una beca de Cooperación del Programa Intercampus para realizar tareas de ayudantía de Trabajo Social en la Universidad Nacional Autónoma de Honduras, he tenido la oportunidad de conocer la situación de la mujer hondureña, especialmente de aquéllas que se encuentran en situación de marginación y desventaja social.

A medida que la pobreza corroe, los niveles de violencia aumentan. Hay una relación dialéctica entre las condiciones materiales de existencia y las ideas, sentimientos, actitudes y comportamientos que hombres y mujeres expresan en sus relaciones cotidianas.

Bajo la premisa anterior, podemos entender que en la sociedad hondureña los niveles de violencia están socavando las bases de fraternidad humana. Las mujeres son más vulnerables ante la violencia ejercida en los diferentes ámbitos de la vida y en las relaciones que establecen por afecto o por salario. Esa vulnerabilidad es el «regalo» del sistema de valores masculino que las ve y las toma como mercancía y, además, las culpabiliza de lo que les ocurre.

El objetivo, pues, de este artículo, es dar a conocer la situación de especial indefensión y vulnerabilidad en que se encuentran las mujeres en un país tan alejado, a nivel socioeconómico, del nuestro, pero con el que, como con el resto de países iberoamericanos, existen tantos lazos.

\section{BREVE REFERENCIA AL PAÍS}

Antes de comenzar a exponer algunos datos acerca de la mujer hondureña, creo necesario hacer una breve descripción de la situación política, económica y social de Honduras.

La república de Honduras se encuentra en Centroamérica, en la franja estrecha que une América del Norte con América del Sur. Honduras 
limita al noroeste con Guatemala, al suroeste con El Salvador y en el sureste con Nicaragua.

\subsection{Aspectos socioeconómicos, demográficos y culturales}

El PIB de Honduras es alrededor de 3.500 millones de dólares. En 1991 la renta per cápita era de 570 dólares. La economía se basa en la actividad agrícola y está influenciada por las condiciones de los mercados internacionales.

Existen aproximadamente 21 centros poblados con la categoría de ciudades con más de 10.000 habitantes, en las cuales reside el $80 \%$ de la población registrada como urbana.

La población es joven, con un $46 \%$ menores de 15 años y una edad media de 17 '5 años; el número de habitantes prácticamente se ha quintuplicado en los últimos 60 años y actualmente se estima en 5'2 millones de habitantes, que será el doble en un período de 23 años. Persiste un claro predominio de la población rural.

La fecundidad urbana actual es de 3'7 hijos por mujer, con claras diferencias respecto a las zonas rurales donde se da una media de 7 hijos.

Los principales indicadores sociales reflejan un $32 \%$ de analfabetismo en la población adulta a nivel nacional, siendo este valor del $42 \%$ en el área rural. En 1990, el 40\% de la población ocupaba la clase más pobre, recibiendo el $7^{\prime} 7$ del total del ingreso nacional, mientras que el $10 \%$ de la población ocupaba el estrato de mayor ingreso, recibiendo el $47 \%$ del ingreso nacional por trabajo.

Las enfermedades más frecuentes son las respiratorias (las gripes), las gastrointestinales (amebiasis), las provocadas por picaduras de insectos y el cólera por no tomar precauciones higiénicas.

En la década actual, el modelo de desarrollo se caracteriza por un programa de reforma económica orientado hacia la estabilidad macroeconómica, la disminución del tamaño del Estado, el fortalecimiento del sector privado y la implicación de los gobiernos locales.

Desde el punto de vista político, Honduras es un sistema republicano y representativo. En los últimos doce años los partidos mayoritarios, liberal y nacional, han ganado las elecciones. Actualmente se encuentra gobernando el partido liberal.

\section{LA MUJER HONDUREÑA}

Valga esta breve introducción acerca de las características más relevantes del país para centrarnos en las condiciones de la mujer hondu- 
reña. Es evidente que en un país pobre, las mujeres van a sufrir por su doble condición de oprimida por el sistema y sus desigualdades y por el varón.

A continuación se exponen algunos artículos de la Declaración de Derechos de Honduras del Instituto Interamericano, en lo que se refiere al tema de la mujer.

Art. 16

1. Las mujeres y los hombres, a partir de la edad núbil, tienen derecho, sin restricción alguna por motivos de raza, nacionalidad o religión, a casarse y fundar una familia; y disfrutarán de iguales derechos en cuanto al matrimonio, durante el matrimonio y en caso de disolución del matrimonio.

2. Sólo mediante libre y pleno consentimiento de los futuros esposos podrá contraerse el matrimonio.

3. La familia es el elemento natural y fundamental de la sociedad y tiene derecho a la protección de la sociedad y Estado.

Art.17

1. Toda mujer tiene derecho a la propiedad, individual y colectivamente.

2. Ninguna mujer será privada arbitrariamente de su propiedad.

Art.18

Toda mujer tiene derecho a la libertad de pensamiento, de conciencia y de religión; este derecho incluye la libertad de cambiar de religión o su creencia individual y colectivamente, tanto en público como en privado, por la enseñanza, la práctica, el culto y la observancia.

Art. 19

Toda mujer tiene derecho a la libertad de opinión y de expresión. Este derecho incluye el de no ser molestada por causa de sus opiniones, el de investigar y recibir informaciones y opiniones, y el de difundirlas, sin limitación de fronteras, por cualquier medio de expresión.

Art. 20

1. Toda mujer tiene derecho a la libertad de reunión y de asociación pacífica.

2. Ninguna mujer podrá ser obligada a pertenecer a una asociación.

De lo anterior se desprende que, si bien la legislación hondureña formalmente protege sin discriminación al hombre y a la mujer, en la realidad no es así. En Honduras, en teoría, la mujer tiene el derecho a la democracia, a la vida, al trabajo, a expresarse y movilizarse libre- 
mente, a organizarse, a ser tratada con dignidad y a la paz, pero en una sociedad donde las condiciones de vida son de pobreza y miseria, esos derechos se violan constantemente.

La crisis económica y social del país, agrava, aun más, la situación de la mujer y la marginación y subordinación a que ha sido sometida. De esta forma, dos son las variables que se conjugan: sexo y pobreza, siendo oprimida directa y profundamente por la condición de ser pobre y de ser mujer.

Es la mujer hondureña, en cualquier sector social o cultural enmarcado en la pobreza, víctima de abuso físico, psíquico y sexual, de violencia doméstica, de abandono, de desvalorización y de prostitución.

En Honduras, un método de intimidación que se utiliza contra quienes presionan para que se investiguen los abusos de derechos humanos son las amenazas de muerte. A continuación cito un ejemplo de este «método»: el 2 de marzo de 1994, B.O., coordinadora general del Comité de Familiares de Detenidos Desaparecidos de Honduras (COFADEH), estaba llamando por teléfono cuando la línea fue interceptada por un individuo que dijo ser coronel. Este amenazó a B.O. con hacerla «desaparecer» y matarla a ella y a su familia. Las amenazas telefónicas se repitieron varias veces a lo largo del día y de nuevo doce días más tarde. Algunas veces se escuchaba una marcha fúnebre ${ }^{1}$.

Así, desde mi experiencia, pretendo resaltar en estas líneas, aspectos de la vida de la mujer hondureña, así como algunos de los programas de ayuda con los que cuenta.

\subsection{La situación laboral}

El empleo (trabajo remunerado) otorga al individuo unas coordenadas de referencia en la sociedad; permite interaccionar con los otros y otorga un status y una autoestima permitiendo la participación en la vida pública.

Partiendo de esta idea, la distinción entre empleo y trabajo no sólo se traslada al terreno económico, sino que condiciona y marca unas pautas de convivencia.

En Honduras un porcentaje alto de mujeres carece de un trabajo remunerado, y es el trabajo doméstico la ocupación principal. Trabajo que favorece que los roles «hombre-mujer» estén todavía más marcados, y en la sociedad hondureña esta distinción va seguida de una fuerte dependencia y subordinación. 
En las ciudades podemos distinguir tres ocupaciones generadoras de situaciones de injusticia:

1. El trabajo industrial.

2. El trabajo doméstico (propio o ajeno).

3. Venta ambulante.

\subsubsection{El trabajo industrial}

La mujer obrera, en las grandes ciudades hondureñas, es discriminada desde el momento que entra a formar parte de la empresa. Además de ocupar cargos menos cualificados su trato es distinto al del hombre:

- Recibe un salario más bajo.

- Es acosada sexualmente.

- Los despidos son injustos e injustificados.

- Se violan las medidas de seguridad e higiene.

- Se penalizan las conductas colectivas (protestas, huelgas).

- No se pagan las indemnizaciones por riesgos profesionales.

En las zonas maquileras se incrementan todas estas violaciones, puesto que el marco legal para su funcionamiento deja fuera la protección de la mano de obra.

La escasa formación de las mujeres, agrava aún más todas estas situaciones de injusticia. $\mathrm{El}$ acceso a enseñanzas superiores es difícil en las grandes ciudades, e impensable para las mujeres de las zonas rurales.

\subsubsection{El trabajo doméstico}

Cuando hablamos de trabajo doméstico nos referimos, por un lado, al trabajo que las mujeres realizan en sus hogares, el ser «ama de casa» y por otro, al trabajo que muchas mujeres realizan en otras casas, trabajo que en Honduras pocas veces es remunerado.

Si hablamos de la primera situación, tenemos que destacar un dato importante, es frecuente encontrar mujeres que se ocupen de las tareas domésticas, pero en las familias con un nivel medio-bajo es la «chica» la que realiza las tareas de la casa, las compras, se ocupa de los niños...

En ciudades importantes, es frecuente encontrar mujeres que «trabajan» para otros en condiciones de verdadera injusticia. En pleno siglo XX, en Honduras las «criadas» (como aún se les llama allí), realizan las tareas domésticas a cambio de subsistir . Permanecen todo el día en la casa, se ocupan de los niños, poseen su espacio físico separado del resto de la casa y tienen muy claro quién es el señor y la señora. 
Algunas de estas mujeres poseen su propia familia y tienen hijos a los que no ven. Aquellas «más afortunadas» poseen sus pequeños ahorros que mandan a sus familias, ahorros conseguidos o bien por un pequeño sueldo o, en la mayoría de los casos, por propinas y regalos de las familias.

Sus familias suelen vivir en zonas rurales, y son las abuelas las que se ocupan de los niños que seguirán su misma suerte. Otras mujeres, menos afortunadas, (algunas, niñas todavía) no tienen familia ni donde ir.

\subsubsection{La venta ambulante}

Muchas mujeres hondureñas salen a la calle a vender aquello que saben hacer. La mayoría de los productos que se ofrecen son fruto de la agricultura y es aquí la mujer campesina la que juega un papel importante.

También se venden dulces hechos por ellas o tortillas de maíz que preparan en sus casas. Las condiciones higiénicas son mínimas y los productos suelen estar en mal estado y además han de venderse día a día, lo que produce una situación muy inestable.

Tenemos que destacar también, la importancia de la mendicidad femenina, que aunque se encuentra muy por debajo de la mendicidad infantil (que alcanza cifras muy elevadas), supone un indicador importante del dominio del hombre.

En las zonas rurales, la mujer es parte activa en la agricultura, sobretodo en el proceso de café y tabaco. La mano de obra barata supone, en las grandes explotaciones agrícolas, que la mujer sea la que trabaje la tierra sin obtener una relación directa entre su trabajo y el dinero que recibe.

En las pequeñas tierras, es la mujer la encargada del cultivo y de la posterior venta de los productos en las ciudades, pero la mujer no tiene derecho a ser propietaria de la tierra, estando mínimamente amparada por la legislación social.

\subsection{En la familia}

«Un hombre que se casa con una mujer activa, emprendedora, independiente, no descansa hasta que la tiene domesticada en la casa con los hijos y los quehaceres del hogar, confinada a esas cuatro paredes, 
desactualizándose, perdiendo su autonomía, su coraje y su confianza en ella misma». ${ }^{2}$

En las familias hondureñas, los roles masculinos y femeninos están muy determinados por la tradición, y los cambios en la distribución del trabajo son inexistentes.

Existen tareas para el hombre y la mujer, es decir, tareas que son de hombres y de mujeres. Actualmente, en muchos hogares, la mujer ha de pedir permiso si va a salir, dar explicaciones e incluso comer cuando todos estén servidos. Muchas mujeres todavía siguen comiendo después del marido, no sentándose a la mesa con él.

El sentido que posee la familia es un sentido de unión, de fidelidad al esposo y de sometimiento a él. Naturalmente, este sentido familiar tan sólo lo es para la mujer. La «infidelidad» de la mujer se castiga todavía en las zonas más deprimidas, mientras que, por el contrario, la mayoría de hombres tienen hijos fuera del matrimonio, hijos a los que no reconocen legalmente.

En el campo, la situación de la mujer todavía se agrava más, ya que es la mujer más joven la encargada de realizar las tareas de la casa y del campo y tiene por obligación cuidar a toda la familia, compuesta por varias generaciones.

\subsection{La sexualidad en la mujer}

En la sociedad hondureña nos encontramos con estructuras mentales y personalidades socializadas para la sexualidad, cuyo objetivo es vivir para la procreación y para la satisfacción sexual de sus compañeros.

Partiendo de ahí, es difícil entender una educación sexual donde participen hombre y mujer y donde las medidas de seguridad y de prevención estén presentes.

A la mujer se le enseña en el hogar, en la escuela, en la iglesia y en los medios de comunicación que ha de ser bella, tentadora y que su fin primordial en la sociedad es la procreación. Cuando la niña escucha en la escuela que «una mujer si no es madre no es mujer completa» o percibe que una mujer a los 30 o 40 años es sujeto de descalificativos como «solterona» y por tanto amargada, va llegando a la conclusión de que lo más importante para ser una mujer socialmente aceptada es ser madre y debe tener un hombre al lado. ${ }^{3}$

2 MARINA ORELLANA, Olga.: «Imagen o mujer». Entre amigas, $n^{\circ} 16$. Tegucigalpa (Honduras C.A.), julio 1994, pág. 9.

3 NOEMI MENDOZA, Eda. : «Las enfermedades de transmision sexual y el género». Entre amigas, $n^{\%}$ 3. Tegucigalpa (Honduras C.A), julio 1994, pág.13. 
Las actitudes de las mujeres con respecto a la sexualidad, impiden el autodiagnóstico de las enfermedades y que busquen ayuda profesional para sus enfermedades genitales; de esta forma hay mujeres que viven toda su vida con una infección, sin conocer su causa y sin poner ningún remedio para la curación.

En Honduras las enfermedades de transmisión sexual aumentan cada vez más y los casos de SIDA están alcanzando unas dimensiones alarmantes.

Todos estas situaciones se agravan más por la gran influencia que ejerce la iglesia y el elevado número de sectas religiosas que existen.Desde allí se lanza a la mujer mensajes de conformismo, de sufrimiento y de sometimiento.

\section{ACTUACIONES: PLAN DE GOBIERNO. PRAF.}

El gobierno de Honduras ha diseñado un plan estratégico para el período 1994-1995. Los propósitos que se destacan son:

- Objetivo principal de las políticas y estrategias del nuevo gobierno: el desarrollo humano.

- Clara y explícita opción por los pobres y grupos más vulnerables: infancia, MUJER y juventud.

- Fortalecimiento democrático, participación popular, concertación nacional.

- Alcanzar un 35\% de gasto social/gasto de gobierno.

- Reiteración del compromiso de alcanzar las metas del Plan de Acción Nacional 1992-2000.

- Areas prioritarias de la política:

- Seguridad alimentaria.

- Atención primaria de salud.

- Educación básica.

- Agua y saneamiento.

- Fortalecimiento del sistema de planificación para integrar los aspectos económicos y sociales para impulsar un solo proceso de desarrollo.

Como podemos observar, dentro de este programa, la mujer aparece como grupo vulnerable enmarcado dentro de la pobreza. Podemos destacar, como un recurso importante para la mujer hondureña, el llamado Programa de Asignación Familiar (PRAF), ya que en él se contemplan actuaciones concretas con y para las mujeres. ${ }^{4}$

4 PRAF: Programa de Asignación Familiar. Memoria 1990-1993. Honduras. Presidencia de la República. 
El PRAF es un amplio programa de política social destinado a alcanzar objetivos generales y específicos dentro de los planes del gobierno en favor de tres sectores bastante olvidados de la población: la mujer sola, los niños escolares pobres y el sector poblacional de la tercera edad.

Para la mujer, el programa intenta desarrollar facultades que permitan generar iniciativas de autosostenimiento y contribución al progreso social.

Estos proyectos de desarrollo dan cobertura a situaciones de marginación y pobreza. Tanto en las áreas rurales como en los barrios marginales de las ciudades, se dan numerosos casos de abandono de mujeres y de mujeres solas en la más absoluta pobreza.

Los objetivos del PRAF se concretan en:

1. Propiciar el desarrollo de proyectos de compensación social dirigidos a aquellos sectores y grupos poblacionales mayoritarios más vulnerables de las comunidades hondureñas donde las actividades serán orientadas principalmente al desarrollo de la mujer en estrecha coordinación con entidades que ejecuten acciones de compensación y desarrollo social dentro del marco general de la política social del país.

2. Promover proyectos complementarios en los cuales las subvenciones constituyan un mecanismo de estímulo para apoyar programas permanentes de carácter productivo, que le permitan solucionar sus necesidades básicas, así como la mejora de su bienestar social, a través de la capacitación y el desarrollo de los recursos locales mediante la autogestión.

Los proyectos que el PRAF destaca para las mujeres son:

- Proyecto Bono mujer jefe de familia (PBMJF). Se trata de la entrega de un valor de 20.00 lempiras (2 dólares aprox.), durante 10 meses, a mujeres con niños matriculados en la escuela primaria, que no puedan costear la educación de sus hijos.

Supone un ingreso adicional a las mujeres solas que tienen hijos, además de garantizar la educación de los niños.

- Proyecto Bono materno-infantil (PBMI). Consiste en la entrega de un bono alimentario de 20.00 lempiras a niños menores de 5 años y a madres embarazadas o en período de lactancia.

Los objetivos que se persiguen son:

1. Ofrecer ayuda alimentaria para contribuir a mejorar las necesidades básicas en el consumo diario de proteínas y calorías.

2. Aumentar la cobertura de los servicios básicos de salud en control prenatal, saneamiento ambiental, control de enfermedades infectocontagiosas, educación en saluda y educación alimentaria. 
- Proyecto Formación ocupacional (FPO).

La principal función de este proyecto es la de mejorar la condición humana de la mujer jefe de familia educándola en cursos técnicos de corta duración que le permitan incorporarse al mundo del trabajo con mayor eficiencia que antes. La capacitación es, sobre todo, ocupacional, con el objeto de estimular la creación de actividades productivas, pero también se incluyen aspectos de prevención de la salud, higiene, organización... El proyecto busca, en conclusión, incorporar a la mujer que vive bajo la línea de la pobreza a un proceso de autodesarrollo.

Por medio del proyecto, ha sido posible llegar directamente a las áreas más pobres del país y permite la superación de personas que se han mantenido, durante mucho tiempo, al margen del desarrollo.

La capacitación se realiza por dos vías, directamente por el PRAF o bien por organismos privados de desarrollo que cooperan en Honduras.

Los objetivos del proyecto de formación ocupacional se centran en:

1. Desarrollar el potencial productivo y creativo de las madres de escasos recursos.

2. Brindar capacitación con el objeto de que las beneficiarias sean capaces de iniciar actividades productivas para alcanzar la autosuficiencia económica.

3. Desarrollar en las beneficiarias actitudes que promuevan una base mínima de organización comunitaria.

4. Mejorar las condiciones de vida de las madres beneficiadas con los bonos del PBMJF.

El FPO, comprende, a su vez, numerosos proyectos específicos, desde la formación básica en asuntos administrativos hasta el dominio de las técnicas sencillas para fabricar objetos de utilidad práctica o la siembra y cosecha de productos agrícolas. Algunos de los proyectos que se vienen desarrollando en la actualidad son:

- Cría de animales.

- Cultivo del junco.

- Cultivo de papa.

- Confituras.

- Elaboración de jaleas...

Todos estos proyectos han devuelto la esperanza a muchas mujeres aisladas y marginadas por la pobreza. Es evidente, pues, que desde el Gobierno se intenta paliar globalmente la situación de pobreza y subdesarrollo pero, desde mi punto de vista, haría falta mucho más que actuaciones desarrollistas para cambiar la situación real de la mujer. 
Es posible que esas actuaciones mejoren las condiciones de vida, pero la situación de opresión y sometimiento de la mujer hacia el hombre es un aspecto difícilmente modificable en un país con valores tan arraigados acerca de la masculinidad y el machismo.

Cambiar esto supone cambiar la ideología, trabajar desde la familia, desde las bases, a nivel educacional y cultural para intentar que las mujeres tomen conciencia de que sus derechos son idénticos a los de los hombres. Creo que, desde el Trabajo Social, hay una gran tarea que realizar en este sentido: asumir que para el cambio de la sociedad hay que comprender los efectos del sexismo en la vida de las personas. No habrá cambio social si no se produce el cambio en la vida de la mujer. 